\title{
BMJ Open Impact of previous open renal surgery on the outcomes of subsequent percutaneous nephrolithotomy: a meta-analysis
}

\author{
Henglong Hu, Yuchao Lu, Lei Cui, Jiaqiao Zhang, Zhenyu Zhao, Baolong Qin, \\ Yufeng Wang, Qing Wang, Shaogang Wang
}

To cite: Hu H, Lu Y, Cui L, et al. Impact of previous open renal surgery on the outcomes of subsequent percutaneous nephrolithotomy: a meta-analysis. BMJ Open 2016;6:e010627. doi:10.1136/bmjopen-2015010627

- Prepublication history and additional material is available. To view please visit the journal (http://dx.doi.org/ 10.1136/bmjopen-2015010627)

Received 23 November 2015 Revised 8 March 2016 Accepted 29 March 2016

CrossMark

Department and Institute of Urology, Tongji Hospital, Tongji Medical College, Huazhong University of Science and Technology, Wuhan, Hubei, China

Correspondence to Dr Shaogang Wang; sgwangtjm@163.com

\section{ABSTRACT}

Objective: The aim of this study was to systematically compare the perioperative outcomes of percutaneous nephrolithotomy in patients with or without previous ipsilateral open renal surgery (POS).

Design: Systematic searches of the PubMed, Web of Science and Cochrane Library databases were used to identify relevant studies, and, following literature screening and data extraction, a meta-analysis was performed.

Results: 17 retrospective cohort studies involving 4833 procedures (4784 patients) were included. No statistically significant differences were observed between patients with or without POS in terms of supracostal access; single/multiple tracts; metal dilator need; time required to access the collecting system; fluoroscopic duration; demand for analgesics; hospital stay; final stone-free rate; and risk of developing certain complications (eg, fever, haemorrhage, haemo/hydro/pneumothorax, blood transfusion, urinary tract infection and sepsis) as well as regarding the risk of total complications. Patients with POS, however, had a greater drop in haemoglobin (weighted mean difference (WMD), $1.78 \mathrm{~g} / \mathrm{L} ; 95 \% \mathrm{Cl} 1.09$ to $2.47 ; p<0.00001$ ) and higher risk of bleeding that required angiographic embolisation (relative risk (RR), $3.73 ; 95 \% \mathrm{Cl} 1.36$ to 10.21; $p=0.01$ ). In addition, patients with POS also had a lower initial stone-free rate (RR, $0.96 ; 95 \% \mathrm{Cl}$ 0.92 to $0.99 ; p=0.007)$ and more secondary treatment (RR, $1.61 ; 95 \% \mathrm{Cl} 1.09$ to $2.37 ; p=0.02$ ). Sensitivity analysis produced comparable results except for differences in operative time and initial stone-free rate, which did, however, prove to be statistically insignificant $(p=0.16$ and 0.69 , respectively).

Conclusions: Current evidence suggests that percutaneous nephrolithotomy in patients with POS is associated with a significantly greater drop in haemoglobin, higher risk of requiring angiographic embolisation and auxiliary procedures, potentially longer operative time, and lower initial stone-free rate than percutaneous nephrolithotomy in patients without POS.

\section{Strengths and limitations of this study}

- This is the first systematic review and meta-analysis to compare the perioperative outcomes of percutaneous nephrolithotomy in patients with or without previous ipsilateral open renal surgery.

- Methodological quality of each study was assessed using the Newcastle-Ottawa Scale for non-randomised controlled trials, and heterogeneity test, bias assessment, meta-analysis and sensitivity analysis were also conducted.

- Substantial heterogeneity was observed for several outcomes.

- The risk of selecting and reporting bias cannot be totally excluded due to the retrospective approach of data collection in the included studies.

\section{INTRODUCTION}

The lifetime risk of kidney stone formation is approximately $11 \%$ for men and $7 \%$ for women, which has a tendency to increase with changes in diet and climate. ${ }^{1}$ It is anticipated that other pre-existing medical conditions, such as diabetes and obesity, will further increase an individual's risk of developing nephrolithiasis. ${ }^{2}$ Besides a high prevalence, renal stone disease also has a tendency to recur if left untreated, with a reported recurrence rate as high as $50 \%$ at 5 years and $80-90 \%$ at 10 years, respectively. ${ }^{3}$

Percutaneous nephrolithotomy (PCNL), first reported by Fernstrom and Johansson in 1976, has almost replaced open surgery as the main treatment for large or multiple kidney stones, and has been used in cases of failed shock wave lithotripsy, in most countries. ${ }^{45}$ However, open renal surgery and its influence have not become obsolete. Some patients treated today have undergone open 
nephrolithotomy in the past due to the high recurrence rate of urolithiasis. Furthermore, open surgery still plays an essential role in special medical circumstances where minimally invasive interventions may not be suitable, and in many peripheral regions of developing countries, where PCNL is not freely available. ${ }^{6}{ }^{7}$ With the recurrence rate for renal stones, these patients may also need PCNL intervention in the future. Patients with previous open renal surgery (POS) will often have retroperitoneal scar tissue around the kidney, distortion of the pelvicaliceal anatomy and, in some cases, bowel displacement. In general, when performing surgery in an anatomical region that has previously been operated on, the surgeon can expect a technical challenge that may be associated with a longer operating time, higher complication rate and, possibly, a lower success rate.

Does POS affect the efficiency and safety of subsequent PCNL? Various studies have sought to compare the outcomes of PCNL in patients with or without a history of open renal surgery. ${ }^{8-24}$ Their results have not been entirely consistent or have even been contradictory, with some reporting lower success rates and/or higher complication risks associated with POS,,$^{10} 1316202123$ while others have found no significant differences between the POS and non-previous open renal surgery (nPOS) groups. ${ }^{8} 9 \begin{array}{lllllll} & 11 & 12 & 17-19 & 22 & 24 & \text { Despite numerous }\end{array}$ studies being carried out since the 1980s, this problem has remained a contentious issue that is still debated today. The aim of this study was to perform a systematic review of all available evidence comparing surgical outcomes of PCNL in patients with or without POS, and to provide an answer using a meta-analysis approach.

\section{MATERIALS AND METHODS}

A study protocol was developed and is provided as an online supplementary material file.

\section{Literature searches and study selection}

A systematic literature database search in PubMed, Web of Science and the Cochrane Library was performed to identify relevant studies, on 10 September 2015. The search was limited by neither year nor language, and followed Cochrane standards and guidelines of Preferred Reporting Items for Systematic Reviews and MetaAnalyses. ${ }^{25}$ The strategy was designed to retrieve all published original articles containing the following search terms: ('lumbotomy' OR 'open') AND ('percutaneous nephrolithotomy' OR 'percutaneous nephrolithotripsy' OR 'PCNL' OR 'PNL'). Two authors, namely HH and YL, independently screened all of the citations returned from the search strategy, to identify potentially eligible studies. Studies comparing the perioperative outcomes of PCNL in patients with or without POS were screened further. Conference abstracts were not included, as they were deemed methodologically inappropriate. Disagreements were resolved through discussions until a consensus was reached.

\section{Data extraction and study quality assessment}

The authors identifying the included studies also independently extracted and summarised the following data: participant characteristics, study design and duration, sample size, inclusion/exclusion criteria, matching criteria and reported perioperative outcomes. The methodological quality of each study was assessed by the two authors mentioned above using the Newcastle-Ottawa Scale for non-randomised controlled trials. ${ }^{26}$ Possible publication bias was assessed using funnel plots of the outcome comparisons.

\section{Statistical analysis}

A meta-analysis was performed using Review Manager Software V.5.3 (RevMan V.5.3, The Cochrane Collaboration, Oxford, UK). The weighted-mean difference (WMD) and relative risk (RR) with $95 \%$ CIs were used as the summary statistics for continuous and dichotomous variables, respectively. For studies presenting continuous data as means and ranges, the SDs were estimated using the methodology described by Hozo et al. ${ }^{27}$ Heterogeneity between studies was assessed using the $\chi^{2}$ test and $\mathrm{I}^{2}$ statistics. Pooled estimates were calculated using a fixed-effects model, unless significant heterogeneity was detected, in which case a random-effects model was applied. The pooled effects were determined using a z-test. A two-sided $p$ value $<0.05$ was used to indicate statistical significance. Funnel plots were generated in order to screen for potential publication bias. Additional sensitivity analyses were performed by ruling out studies in which participants of the two groups were not equally matched.

\section{RESULTS}

\section{Literature searches and characteristics of the included} studies

Figure 1A illustrates the flow diagram of both included and excluded studies identified. After referring to the full texts, 17 studies involving 4833 procedures (4784 patients) of which 1431 were in the POS group and 3402 in the nPOS group, were enrolled for analysis. Full-text screening was performed for three studies and these were finally excluded because of lack of a control group or because the data in the studies were confused. ${ }^{28}$ The characteristics of those identified studies are summarised in table 1. Eight of the studies were conducted in Turkey, two in Iran, two in India and one each in Brazil, China, Egypt, Israel and Thailand. All of the studies were retrospective cohort studies, and it is impossible to have designed them as randomised controlled studies, for patients could not be randomly divided into groups with or without POS. The inclusion criteria of the POS group were previous ipsilateral open stone surgery in 16 studies $^{8-16}{ }^{18-24}$ and open renal operations in one. ${ }^{17}$ The reasons that patients required open renal surgeries in the last study were not explicitly described, although they were probably due to stone diseases. ${ }^{17}$ Conversely, the inclusion criteria of the nPOS group 

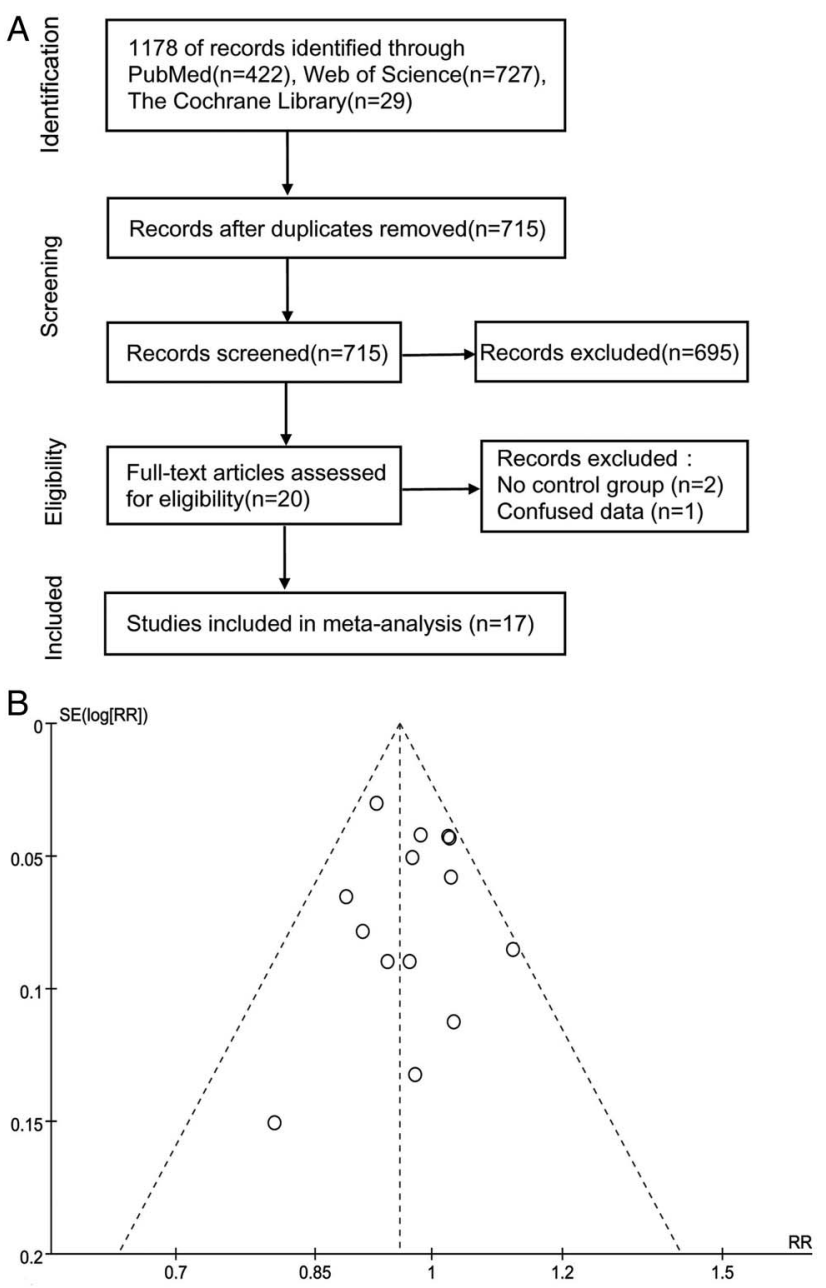

Figure 1 (A) Flowchart of the studies selection process. (B) Funnel plot of initial stone-free rate.

were primary PCNL without POS. All procedures were carried out under general anaesthesia with the guidance of fluoroscopy, with the exception of one clinical team from China, which used epidural anaesthesia under the guidance of ultrasound. ${ }^{19}$ All of the patients were placed in the prone position with the majority receiving standard PCNL; however, in some studies, selected patients received minimally invasive $e^{17192124}$ (tract size $\leq 22 \mathrm{~F}$ ) or tubeless PCNL instead. ${ }^{11} 1516$ Most trials used pneumolithotripsy, ${ }^{13-15}$ 18-20 24 while others used ultrasonic lithotripter $^{8}{ }^{9}$ or were mixed. ${ }^{10} 121617$ The studies were rated according to the Newcastle-Ottawa Scale as being relatively high in quality. The baseline characteristics were directly comparable between the two groups in most studies. ${ }^{8}$ 10-12 14-20 24 Significant differences were observed, however, in respect to the sex ratio, age or renal stone burden, in four studies, which are also shown in table $1 .{ }^{9} 132123$ Additionally, a sensitivity analysis was performed in order to detect and rule out any potential bias associated with the effects of such studies on the results as a whole. We analysed possible publication bias by generating funnel plots of all the evaluated comparisons of outcomes. As an example, figure 1B represents the funnel plot of the comparison for initial stone-free rate (SFR), which included the most patients. It shows no obvious asymmetry, suggesting that publication bias was not significant.

\section{Meta-analysis of perioperative outcomes}

A meta-analysis of perioperative outcomes is summarised in table 2. The forest and funnel plots for each comparison are represented in online supplementary figure 1-42. As shown in table 2, the heterogeneity in most comparisons was moderate or low. No statistically significant differences were observed between POS and nPOS groups in terms of supracostal access (RR, 0.89; $95 \%$ CI 0.72 to $1.11 ; \mathrm{p}=0.31$ ), single tracts (RR, 1.00 ; $95 \%$ CI 0.97 to $1.03 ; \mathrm{p}=0.89$ ), multiple tracts ( $R R$, $1.11 ; 95 \%$ CI 0.83 to $1.47 ; \mathrm{p}=0.49)$, metal dilator need (RR, 5.02; 95\% CI 0.96 to 26.19; $\mathrm{p}=0.06$ ), time required to access the collecting system (WMD, $0.85 \mathrm{~min}$; $95 \%$ CI -0.82 to 2.53; $\mathrm{p}=0.32$ ), fluoroscopic duration (WMD, $0.01 \mathrm{~min}$; $95 \%$ CI -0.24 to $0.25 ; \mathrm{p}=0.95$ ), demand for analgaesics (WMD, $6.06 \mathrm{mg} ; 95 \%$ CI 0.12 to 11.99; $\mathrm{p}=0.05$ ), hospital stay (WMD, $0.06 \mathrm{~d}$; $95 \%$ CI -0.10 to $0.22 ; \mathrm{p}=0.47)$, final stone-free rate (RR, $1.00 ; 95 \% \mathrm{CI}$ 0.98 to $1.03 ; \mathrm{p}=0.78$ ), the risk of total complications ( $R R$, 1.03 ; $95 \%$ CI 0.89 to $1.19 ; \mathrm{p}=0.69$ ) and risk of developing certain complications such as fever (RR, $1.05 ; 95 \%$ CI 0.70 to $1.58 ; \mathrm{p}=0.80$ ), haemorrhage ( $\mathrm{RR}, 1.02 ; 95 \%$ CI 0.71 to $1.46 ; \mathrm{p}=0.93$ ), haemo/hydro/pneumothorax (RR, 0.93 ; 95\% CI 0.51 to 1.69 ; $\mathrm{p}=0.80$ ), blood transfusion (RR, $1.10 ; 95 \%$ CI 0.86 to $1.39 ; \mathrm{p}=0.45$ ), urinary tract infection (RR, 1.42; 95\% CI 0.93 to 2.15; $\mathrm{p}=0.10$ ) and sepsis (RR, $1.07 ; 95 \%$ CI 0.31 to $3.66 ; \mathrm{p}=0.92$ ). Patients with POS, however, had a greater drop in haemoglobin (WMD, $1.78 \mathrm{~g} / \mathrm{L} ; 95 \%$ CI 1.09 to 2.47; $\mathrm{p}<0.00001)$ accompanied by a higher risk of bleeding requiring angiographic embolisation (RR, 3.73; 95\% CI 1.36 to $10.21 ; \mathrm{p}=0.01$ ), lower initial SFR (RR, 0.96; $95 \%$ CI 0.92 to $0.99 ; \mathrm{p}=0.007)$ and more secondary treatment (RR, $1.61 ; 95 \%$ CI 1.09 to $2.37 ; \mathrm{p}=0.02$ ).

\section{Sensitivity analysis}

Further sensitivity analysis was performed by removing studies in which patients' baseline characteristics were not well matched. As shown in table 3, except for differences in operative time and initial SFR, which turned out to be insignificant ( $p=0.16$ and 0.69 , respectively), sensitivity analyses generated comparable results that affected the degree rather than the direction or significance of the effect.

\section{DISCUSSION}

This meta-analysis has demonstrated no statistically significant difference in supracostal access, single/multiple tracts, metal dilator need, time required to access the collecting system, fluoroscopic duration, demand for analgesics, final SFR, hospital stay, risks of certain complications (eg, fever, haemorrhage, haemo-/hydro-/ 
Table 1 Characteristics of included studies

\begin{tabular}{|c|c|c|c|c|c|c|c|c|c|c|c|c|}
\hline Studies & Year & Country & Duration & $\begin{array}{l}\text { Study } \\
\text { design }\end{array}$ & $\begin{array}{l}\text { Study } \\
\text { quality }\end{array}$ & Groups & $\begin{array}{l}\text { Renal } \\
\text { units }\end{array}$ & $\begin{array}{l}\text { Patient } \\
\text { number }\end{array}$ & $\begin{array}{l}\text { Mean/median } \\
\text { age (SD/ } \\
\text { range) (year) }\end{array}$ & Sex M/F & Side L/R & $\begin{array}{l}\text { Stone diameterl } \\
\text { area }(\mathrm{SD} / \mathrm{range}) \\
\left(\mathrm{mm} / \mathrm{mm}^{2}\right)\end{array}$ \\
\hline \multirow[t]{2}{*}{ Netto et $a l^{\beta}$} & 1988 & Brazil & NA & RCS & $8 / 9$ & POS & 84 & 79 & $45(9-72)$ & $47 / 32$ & NA & NA \\
\hline & & & & & & nPOS & 150 & 145 & $49(18-75)$ & $83 / 62$ & NA & NA \\
\hline \multirow[t]{2}{*}{ Basiri et a $\rho$} & 2003 & Iran & 1990-1999 & RCS & $6 / 9$ & POS & 65 & 65 & $40(14-74)$ & $51 / 14^{*}$ & $32 / 33$ & 30 \\
\hline & & & & & & nPOS & 117 & 117 & $43(13-75)$ & $73 / 44^{*}$ & $70 / 47$ & 35 \\
\hline \multirow[t]{2}{*}{ Margel et $a l^{10}$} & 2005 & Israel & 2000-2003 & RCS & $8 / 9$ & POS & 21 & 21 & $52^{*}(41-72)$ & $15 / 6$ & NA & 27 (19) \\
\hline & & & & & & nPOS & 146 & 146 & $45^{\star}(10-78)$ & $96 / 50$ & NA & $29.5(17)$ \\
\hline \multirow[t]{2}{*}{ Lojanapiwat et al ${ }^{11}$} & 2006 & Thailand & NA & RCS & $8 / 9$ & POS & 178 & 175 & $50.64(12.38)$ & $111 / 64$ & $86 / 92$ & $38.6(16.8)$ \\
\hline & & & & & & nPOS & 178 & 175 & 50.61 (12.62) & $114 / 61$ & $96 / 82$ & $38.1(15.5)$ \\
\hline \multirow[t]{2}{*}{ Sofikerim et $a l^{12}$} & 2007 & Turkey & 2005-2006 & RCS & $8 / 9$ & POS & 27 & 27 & $45.4(18-74)$ & $16 / 11$ & $17 / 10$ & $361.3(100-900)$ \\
\hline & & & & & & nPOS & 62 & 62 & $44(18-75)$ & $33 / 29$ & $37 / 25$ & $482.4(84-1000)$ \\
\hline \multirow[t]{2}{*}{ Kurtulus et $a l^{13}$} & 2008 & Turkey & 2003-2007 & RCS & $7 / 9$ & POS & 142 & 142 & $45.7(21-67)$ & $85 / 47$ & NA & $1150(150-11500)^{*}$ \\
\hline & & & & & & nPOS & 186 & 186 & $43.5(18-80)$ & $120 / 66$ & NA & $735(100-5600)^{*}$ \\
\hline \multirow[t]{2}{*}{ Tugcu et $a l^{14}$} & 2008 & Turkey & 2004-2006 & RCS & $8 / 9$ & POS & 55 & 55 & $42(22-70)$ & $22 / 35$ & $27 / 28$ & $385.6(110-730)$ \\
\hline & & & & & & nPOS & 105 & 105 & $45(16-72)$ & $49 / 58$ & $54 / 51$ & $401.1(100-8100)$ \\
\hline \multirow[t]{2}{*}{ Falahatkar et al ${ }^{15}$} & 2009 & Iran & 2005-2007 & RCS & $8 / 9$ & POS & 36 & 36 & $47.4(13.69)$ & $22 / 14$ & $16 / 20$ & $35.33(32.76)$ \\
\hline & & & & & & $\mathrm{nPOS}$ & 68 & 68 & $44(13.50)$ & $31 / 37$ & $31 / 37$ & $35.13(21.56)$ \\
\hline \multirow[t]{2}{*}{ Gupta et $a l^{16}$} & 2009 & India & 2005-2007 & RCS & $8 / 9$ & POS & 66 & 66 & $35.2(10-70)$ & $40 / 26$ & $24 / 42$ & $33(20-60)$ \\
\hline & & & & & & $\mathrm{nPOS}$ & 90 & 90 & $33.5(6-72)$ & $55 / 35$ & $38 / 52$ & $35(22-60)$ \\
\hline \multirow[t]{2}{*}{ Resorlu et al ${ }^{17}$} & 2010 & Turkey & 2006-2009 & RCS & $9 / 9$ & POS & 132 & 132 & $44.1(14-66)$ & $71 / 59$ & $67 / 65$ & $820(520)$ \\
\hline & & & & & & $\mathrm{nPOS}$ & 192 & 192 & $41.2(0.75-70)$ & $112 / 87$ & $95 / 92 / 5$ & $780(430)$ \\
\hline \multirow[t]{2}{*}{ Gupta et al ${ }^{18}$} & 2011 & India & 2009-2010 & RCS & $9 / 9$ & POS & 45 & 45 & $40.6(12.30)$ & $27 / 18$ & $25 / 20$ & $30(23)$ \\
\hline & & & & & & nPOS & 55 & 55 & $35.51(11.10)$ & $36 / 19$ & $30 / 25$ & 28 (15) \\
\hline \multirow[t]{2}{*}{ Zhang et $a l^{19}$} & 2011 & China & 2006-2011 & RCS & $8 / 9$ & POS & 34 & 34 & $54.1(13.80)$ & $12 / 22$ & $20 / 14$ & NA \\
\hline & & & & & & nPOS & 64 & 64 & $54.6(11.80)$ & $24 / 40$ & $35 / 29$ & NA \\
\hline \multirow[t]{2}{*}{ Yesil et $a^{00}$} & 2013 & Turkey & 2007-2010 & RCS & $8 / 9$ & POS & 42 & 42 & $40.61(12.30)$ & NA & NA & 189.57 (94.23) \\
\hline & & & & & & nPOS & 232 & 232 & $44.34(12.75)$ & NA & NA & $177.33(86.18)$ \\
\hline \multirow[t]{2}{*}{ Onal et $a^{21}$} & 2014 & Turkey & 2000-2011 & RCS & $7 / 9$ & POS & 26 & 23 & $8.51(5.17)^{\star}$ & $13 / 10$ & $12 / 14$ & $513(337)$ \\
\hline & & & & & & nPOS & 97 & 88 & $6.29(4.37)^{*}$ & $56 / 32$ & $43 / 54$ & 409 (328) \\
\hline \multirow[t]{2}{*}{ Aldaqadossi et $a^{22}$} & 2015 & Egypt & 2008-2014 & RCS & $8 / 9$ & POS & 48 & 40 & $7.9(4.2)$ & $27 / 13$ & $22 / 26$ & $32(2.9)$ \\
\hline & & & & & & nPOS & 87 & 81 & $7.3(3.50)$ & $49 / 32$ & $48 / 39$ & $32(3.6)$ \\
\hline \multirow[t]{2}{*}{ Ozgor et $a P^{3}$} & 2015 & Turkey & 2002-2015 & RCS & $8 / 9$ & POS & 410 & 410 & $45.4(13.5)$ & $258 / 152$ & $208 / 202$ & $830(630)$ \\
\hline & & & & & & nPOS & 1529 & 1529 & $44.3(13.9)$ & $875 / 654$ & $821 / 708$ & $780(570)$ \\
\hline \multirow[t]{2}{*}{ Telli et $a P^{4}$} & 2015 & Turkey & 2000-2014 & RCS & $8 / 9$ & POS & 20 & 18 & $10.4(4.20)$ & $12 / 6$ & $11 / 9$ & $36.5(24.2)$ \\
\hline & & & & & & nPOS & 44 & 39 & $8.8(4.50)$ & $27 / 12$ & $25 / 19$ & $33.1(21.6)$ \\
\hline
\end{tabular}

*Significantly different between two groups.

(n)POS, (non-) previous open renal surgery group; L/R, left/right; M/F, male/female; NA, not available; RCS, retrospective cohort studies. 
Table 2 Meta-analyses of perioperative clinical outcomes

\begin{tabular}{|c|c|c|c|c|c|c|c|c|c|c|}
\hline \multirow[b]{2}{*}{ Items } & \multirow[b]{2}{*}{ Studies } & \multirow{2}{*}{$\begin{array}{l}\text { Sample } \\
\text { size } \\
\text { nPOS/POS }\end{array}$} & \multicolumn{2}{|c|}{$\begin{array}{l}\text { Tests for } \\
\text { heterogeneity }\end{array}$} & \multirow[b]{2}{*}{ Analysis model } & \multicolumn{2}{|c|}{$\begin{array}{l}\text { Test for overall } \\
\text { effect }\end{array}$} & \multirow{2}{*}{$\begin{array}{l}\text { Event rate } \\
(\%) \\
\text { nPOS/POS }\end{array}$} & \multirow{2}{*}{$\begin{array}{l}\text { RR/WWD } \\
95 \% \mathrm{Cl}\end{array}$} & \multirow[b]{2}{*}{ Favours } \\
\hline & & & $\mathbf{I}^{2}$ & p Value* & & $\bar{Z}$ & p Value* & & & \\
\hline Operative time (min) & $9-12,14-24$ & $1205 / 3066$ & $54 \%$ & 0.006 & Random & 2.04 & 0.04 & - & 3.55 (0.14 to 6.97$)$ & nPOS \\
\hline Supracostal access & $11,12,16,21-23$ & $755 / 2043$ & $0 \%$ & 0.97 & Fixed & 1.02 & 0.31 & $12.8 / 13.5$ & $0.89(0.72$ to 1.11$)$ & POS \\
\hline Single tract & $9-11,13,15,17,19,21,22,24$ & $702 / 1179$ & $0 \%$ & 0.80 & Fixed & 0.14 & 0.89 & $90.5 / 91.5$ & $1.00(0.97$ to 1.03$)$ & None \\
\hline $\begin{array}{l}\text { Requiring multiple } \\
\text { tracts }\end{array}$ & $9-11,13,15,17,19,21,22,24$ & $702 / 1179$ & $0 \%$ & 0.97 & Fixed & 0.68 & 0.49 & $9.5 / 8.5$ & 1.11 (0.83 to 1.47$)$ & nPOS \\
\hline Needing metal dilator & $8,11,13,16$ & $470 / 604$ & $80 \%$ & 0.002 & Random & 1.91 & 0.06 & $8.4 / 16.8$ & 5.02 (0.96 to 26.19$)$ & nPOS \\
\hline $\begin{array}{l}\text { Tract establishing time } \\
\text { (min) }\end{array}$ & 17,24 & $152 / 236$ & $0 \%$ & 0.86 & Fixed & 1.00 & 0.32 & - & $0.85(-0.82$ to 2.53$)$ & nPOS \\
\hline Fluoroscopic time (min) & $17,20-24$ & $678 / 2181$ & $33 \%$ & 0.19 & Fixed & 0.06 & 0.95 & - & $0.01(-0.24$ to 0.25$)$ & nPOS \\
\hline $\begin{array}{l}\text { Analgesics demand } \\
(\mathrm{mg})\end{array}$ & $11,12,16,22$ & $319 / 417$ & $44 \%$ & 0.72 & Fixed & 2.00 & 0.05 & - & $6.06(0.12$ to 11.99$)$ & nPOS \\
\hline $\begin{array}{l}\text { Haemoglobin drop } \\
\text { (g/L) }\end{array}$ & $10,18,20,22-24$ & $697 / 2139$ & $31 \%$ & 0.20 & Fixed & 5.07 & $<0.00001$ & - & 1.78 (1.09 to 2.47 ) & nPOS \\
\hline Fever & $15-18,22$ & $689 / 1934$ & $0 \%$ & 0.84 & Fixed & 0.26 & 0.80 & $4.0 / 5.8$ & 1.05 (0.70 to 1.58$)$ & nPOS \\
\hline Haemorrhage & $8,9,18,20,22,24$ & $304 / 685$ & $64 \%$ & 0.02 & Random & 0.09 & 0.93 & $6.1 / 9.9$ & $1.02(0.71$ to 1.46$)$ & nPOS \\
\hline $\begin{array}{l}\text { Haemo/hydro/ } \\
\text { pneumothorax }\end{array}$ & $8,11,12,16-18,21-23$ & $1016 / 2440$ & $0 \%$ & 0.91 & Fixed & 0.25 & 0.80 & $1.3 / 1.4$ & 0.93 (0.51 to 1.69$)$ & POS \\
\hline Blood transfusion & $8,11-15,17,18,20-24$ & $1245 / 2985$ & $0 \%$ & 0.69 & Fixed & 0.76 & 0.45 & $6.4 / 7.6$ & 1.10 (0.86 to 1.39$)$ & nPOS \\
\hline Urinary tract infection & $9,12,13,17,18,21,22$ & $457 / 753$ & $0 \%$ & 0.91 & Fixed & 1.64 & 0.10 & $6.2 / 8.1$ & $1.42(0.93$ to 2.15$)$ & nPOS \\
\hline Sepsis & $11,14,17$ & $365 / 475$ & $8 \%$ & 0.34 & Fixed & 0.11 & 0.92 & $1.1 / 1.1$ & 1.07 (0.31 to 3.66$)$ & nPOS \\
\hline $\begin{array}{l}\text { Angiographic } \\
\text { embolisation }\end{array}$ & 913192023 & $693 / 2128$ & $37 \%$ & 0.17 & Fixed & 2.55 & 0.01 & $0.3 / 1.0$ & 3.04 (1.29 to 7.16$)$ & nPOS \\
\hline Total complications & $9-18,21-24$ & $1271 / 2956$ & $0 \%$ & 0.99 & Fixed & 0.40 & 0.69 & $14.8 / 16.8$ & $1.03(0.89$ to 1.19$)$ & nPOS \\
\hline Hospital stay(d) & $11,12,14-24$ & $1119 / 2803$ & $63 \%$ & 0.001 & Random & 0.72 & 0.47 & - & $0.06(-0.10$ to 0.22$)$ & nPOS \\
\hline Secondary procedure & $10-14,16,19$ & $523 / 831$ & $64 \%$ & 0.01 & Random & 2.41 & 0.02 & $18.7 / 27.3$ & $1.61(1.09$ to 2.37$)$ & nPOS \\
\hline Initial SRF & $8,9,11-18,21-24$ & $1334 / 2960$ & $15 \%$ & 0.29 & Fixed & 2.68 & 0.007 & $82.2 / 78.9$ & 0.96 (0.92 to 0.99$)$ & nPOS \\
\hline Final SRF & 8-10 13 15-17 19 & $580 / 1013$ & $0 \%$ & 0.79 & Fixed & 0.28 & 0.78 & $92.7 / 93.4$ & 1.00 (0.98 to 1.03$)$ & None \\
\hline
\end{tabular}


Table 3 Sensitivity analysis results

\begin{tabular}{|c|c|c|c|c|c|c|c|c|c|}
\hline \multirow[b]{2}{*}{ Items } & \multirow[b]{2}{*}{ Studies } & \multirow{2}{*}{$\begin{array}{l}\text { Sample size } \\
\text { POS/nPOS }\end{array}$} & \multicolumn{2}{|c|}{$\begin{array}{l}\text { Tests for } \\
\text { heterogeneity }\end{array}$} & \multirow[b]{2}{*}{ Analysis model } & \multicolumn{2}{|c|}{$\begin{array}{l}\text { Test for overall } \\
\text { effect }\end{array}$} & \multirow{2}{*}{$\begin{array}{l}\text { RR/WWD } \\
95 \% \mathrm{CI}\end{array}$} & \multirow[b]{2}{*}{ Favours } \\
\hline & & & $\mathbf{1}^{2}$ & p Value ${ }^{\star}$ & & $\overline{\mathbf{Z}}$ & p Value* & & \\
\hline Operative time (min) & $10-12,14-20,23,24$ & $704 / 1323$ & $60 \%$ & 0.004 & Random & 1.54 & 0.12 & $3.51(-0.96$ to 7.99$)$ & nPOS \\
\hline Supracostal access & $11,12,16,22$ & $319 / 417$ & $0 \%$ & 0.86 & Fixed & 0.86 & 0.39 & 0.87 (0.64 to 1.19$)$ & POS \\
\hline Single tract & $10,11,15,17,19,22,24$ & $469 / 799$ & $0 \%$ & 0.98 & Fixed & 0.62 & 0.54 & 0.99 (0.95 to 1.03$)$ & $\mathrm{nPOS}$ \\
\hline Requiring multiple tracts & $10,11,15,17,19,22,24$ & $469 / 799$ & $0 \%$ & 1.00 & Fixed & 0.62 & 0.53 & $1.12(0.79$ to 1.58$)$ & nPOS \\
\hline Needing metal dilator & $8,11,16$ & $328 / 418$ & $84 \%$ & 0.002 & Random & 1.43 & 0.15 & $6.10(0.51$ to 73.33$)$ & nPOS \\
\hline Fluoroscopic time (min) & $17,20,22,24$ & $652 / 2084$ & $0 \%$ & 0.66 & Fixed & 1.00 & 0.32 & $-0.14(-0.41$ to 0.13$)$ & nPOS \\
\hline Haemoglobin drop (g/L) & $17,18,20,22,24$ & $287 / 610$ & $30 \%$ & 0.22 & Fixed & 5.03 & $<0.00001$ & 2.03 (1.24 to 2.82$)$ & nPOS \\
\hline Haemorrhage & $8,18,20,22,24$ & $239 / 568$ & $71 \%$ & 0.008 & Random & 0.96 & 0.34 & 1.59 (0.62 to 4.06$)$ & nPOS \\
\hline Haemo/hydro/pneumothorax & $8,11,12,16-18,22$ & $580 / 814$ & $0 \%$ & 0.79 & Fixed & 0.03 & 0.98 & 0.99 (0.49 to 2.01$)$ & POS \\
\hline Blood transfusion & $\begin{array}{l}8,11,12,14,15,17,18 \\
20,22,24\end{array}$ & $619 / 1173$ & $0 \%$ & 0.50 & Fixed & 1.00 & 0.32 & $1.20(0.84$ to 1.70$)$ & nPOS \\
\hline Urinary tract infection & $12,17,18,22$ & $224 / 353$ & $0 \%$ & 0.84 & Fixed & 1.72 & 0.09 & $1.60(0.94$ to 2.74$)$ & nPOS \\
\hline Angiographic embolisation & 19,20 & $76 / 296$ & $0 \%$ & 0.32 & Fixed & 3.08 & 0.002 & $18.88(2.91$ to 122.26$)$ & nPOS \\
\hline Total complication & $10-12,14-18,22,24$ & $628 / 1027$ & $0 \%$ & 0.90 & Fixed & 0.37 & 0.71 & $1.04(0.86,1.25)$ & nPOS \\
\hline Hospital stay $(\mathrm{d})$ & $11,12,14-20,22,24$ & $683 / 1177$ & $56 \%$ & 0.01 & Random & 1.02 & 0.31 & $0.09(-0.08$ to 0.25$)$ & nPOS \\
\hline Secondary procedure & $10-12,14,16,19$ & $381 / 645$ & $55 \%$ & 0.05 & Random & 2.57 & 0.01 & $1.81(1.15$ to 2.85$)$ & nPOS \\
\hline Initial SRF & $8,11,12,14-18,22,24$ & $691 / 1031$ & $0 \%$ & 0.66 & Fixed & 0.40 & 0.69 & 0.99 (0.95 to 1.03$)$ & nPOS \\
\hline Final SRF & $8,10,15-17,19$ & $373 / 710$ & $0 \%$ & 0.65 & Fixed & 0.57 & 0.57 & 1.01 (0.98 to 1.04$)$ & POS \\
\hline
\end{tabular}

${ }^{*} p$ Values less than 0.05 were considered statistically significant.

(n)POS, (non-) previous open renal surgery group; RR, relative risk; SFR, stone-free rate; WMD, weighted mean difference. 
pneumothorax, blood transfusion, urinary tract infection and sepsis), or risk of total complications, between patients with or without POS. However, patients with POS had a greater drop in haemoglobin, higher risk of angiographic embolisation, more secondary procedures (eg, relook-PCNL and shock wave lithotripsy), potentially longer operative time and lower initial SFR.

Open renal surgery leads to retroperitoneal scars around the kidney that may adversely affect introduction of the access needle and prevent proper dilatation of the tract in subsequent PCNL procedures. Part of this technical difficulty is reflected in the operative time, which was $3.55 \mathrm{~min}$ longer in the POS group. As expected, many researchers experienced technical difficulty in the establishment of a dilated tract in the POS group; ${ }^{10} 11131518$ although some studies also claim to have encountered no difficulties whatsoever. ${ }^{12} \quad 172122$ This uncertainty and the small difference in operative time generated a $\mathrm{p}$ value of 0.12 in the sensitivity analysis. Urologists who reported no technical difficulties had adopted serial Amplatz dilators. ${ }^{12} 1722$ They found the dilators to work well, even in the presence of dense scarred tissue around the kidney, because the small tip of the instrument could easily pass through the previously smaller dilated tract. ${ }^{17}$ Owing to advancements in instrument development and increasing surgical experience, this difficulty can now be resolved on most occasions, which may explain why there was no difference in the time taken to establish the tract and fluoroscopy that is also partially reflective of the technical challenge.

The process of scarring after open stone surgery may also occur within the collecting system, affecting the rate of kidney stone clearance. The results of this metaanalysis demonstrate that patients with POS have a lower initial SFR and may need more auxiliary procedures; however, no significant difference was observed in initial SFR by sensitivity analysis. On the one hand, the difference in initial SFR between the two groups is very small (RR, 0.96) requiring a large sample size for detection, and on the other, this could also partially arise from differences in the definitions of SFR and pooled studies. Some studies considered residue fragments less than $4 \mathrm{~mm}$ to be stone-free ${ }^{13} 1519$ or a success, ${ }^{11} 12{ }^{24}$ while another used fragments less than $3 \mathrm{~mm},{ }^{8}$ and in the remaining instances, the authors failed to provide a clear definition. From this meta-analysis we can only draw the conclusion that patients with POS have a higher risk of receiving secondary treatment (RR, 1.61; 95\% CI 1.09 to 2.37; $\mathrm{p}=0.02$ ) and can finally reach a SFR as primary patients.

Haemorrhage is one of the most concerning complications following PCNL. If the bleeding is severe, angiography is often required. Five studies, including 2821 patients, reported 13 cases in which angiography was performed. $^{9131920}$ Eight of these patients were found to have arteriovenous fistula. A meta-analysis of these studies showed that patients with POS were associated with a higher risk of angiographic embolisation. Yesil et $a t^{20}$ also reported a higher risk of vascular complications in patients with POS. PCNL after a previous operation is usually performed at a site where having anatomical alterations, inflammation and adhesions could lead to vascular problems. ${ }^{17}$ Furthermore, retroperitoneal and caliceal scarring may surround the kidney, thus reducing its mobility. In these cases, intraoperative manipulation of the nephroscope may produce enough torque to cause lacerations to the kidney, with bleeding. ${ }^{11}{ }^{14}$ This could explain the greater drop in haemoglobin in the POS group. We have also pointed out, however, that major vascular complications requiring angiography embolisation are not common in patients with POS and that a significantly greater drop in haemoglobin does not translate into greater blood transfusion.

Based on the outcomes and experiences of the urologists in this meta-analysis, ${ }^{8-21} 24$ we have outlined some key points below, which need to be considered carefully when performing PCNL in patients with POS:

1. Preoperative evaluation. Preoperative non-contrast helical CT (NCCT) scans and intravenous urography are recommended and of importance when planning the initial access. Except for the kidney stone's characteristics and its relationship with the renal parenchyma, NCCT scans can detect the anatomical distortion and ascertain any possible bowel displacement, while intravenous urography can show the exact anatomy of the renal collecting system.

2. Planning the initial access route. Owing to the difficulty in gaining access to a scarred kidney, and the typical stiffness of the scarred collecting system, it is crucial to select the single access route that will allow maximum kidney stone removal. The tract site should be decided mainly based on stone and anatomical characteristics rather than scar tissue, but making it as far from the surgical scar as possible could facilitate puncture and easy dilation. In addition, lower pole access is associated with a lower complication rate and shorter hospital stay. ${ }^{29}$

3. Tract establishment. There may be some difficulties in dilation due to adhesions and fibrosis. This obstacle can be addressed by using serial fascial dilators in most cases where balloon dilation has resulted in undilated segments. Alternative methods may also include metal dilators and a sharp incision of the fascia.

4. Surgical manipulation. Avoid 'rough' manipulation of the nephroscope as much as possible; this is especially important in reducing some of the major complications in POS patients. As mentioned above, retroperitoneal scarring reduces the mobility of the kidney, and rough intraoperative manipulation of instruments could produce enough torque to cause lacerations and bleeding, and may even result in major vascular complications. Kidney stone removal from a scarred collecting system is difficult, as some stones may be partially embedded in the tissue, 
necessitating careful checking and the use of stone graspers. This is important to improve one-session SFR. 5. Postoperative evaluation and follow-up: pay particular attention to the early recognition of major vascular complications.

This study also has some limitations. As described above, this meta-analysis did not and could not include randomised controlled studies, so there could still be residual confounding when comparing these nonrandomised groups. Two studies did not provide the data on stone size, and only three studies graded postoperative complications according to the Clavien-Dindo Classification System. The perioperative complications in these included studies might have inconsistent definitions and reporting, and the management of such complications was rarely reported; therefore, it was not possible for us to further grade and analyse. In addition, although the funnel plots do not show considerable asymmetry in these comparisons, the risk of selecting and reporting bias cannot be totally excluded due to the retrospective approach of data collection in these studies. Last but not least, statistical significance and clinical significance are not synonyms. Clinical significance should also be considered when interpreting the results of this study.

\section{CONCLUSIONS}

This meta-analysis has demonstrated that, despite having a greater drop in haemoglobin, accompanied by a higher risk of requiring angiographic embolisation and auxiliary procedures, potentially longer operative time and lower initial SFR, subsequent PCNL is not affected by POS on the ipsilateral side.

Contributors $\mathrm{HH}$ and SW conceived and designed the study. $\mathrm{HH}$ and $\mathrm{YL}$ undertook data extraction and quality assessments. LC, JZ and ZZ performed statistical analyses. HH, LC and JZ prepared the figures and tables. All the authors provided inputs and were involved with the interpretation of the results. $\mathrm{HH}$ and $\mathrm{BQ}$ drafted the manuscript. $\mathrm{YW}, \mathrm{QW}$ and $\mathrm{SW}$ revised the manuscript. All the authors have read and approved the final version.

\section{Competing interests None declared.}

Provenance and peer review Not commissioned; externally peer reviewed.

Data sharing statement No additional data are available.

Open Access This is an Open Access article distributed in accordance with the Creative Commons Attribution Non Commercial (CC BY-NC 4.0) license, which permits others to distribute, remix, adapt, build upon this work noncommercially, and license their derivative works on different terms, provided the original work is properly cited and the use is non-commercial. See: http://creativecommons.org/licenses/by-nc/4.0/

\section{REFERENCES}

1. Scales CD Jr, Smith AC, Hanley JM, et al. Prevalence of kidney stones in the United States. Eur Urol 2012;62:160-5.

2. Antonelli JA, Maalouf NM, Pearle MS, et al. Use of the National Health and Nutrition Examination Survey to calculate the impact of obesity and diabetes on cost and prevalence of urolithiasis in 2030 . Eur Urol 2014;66:724-9.

3. Skolarikos A, Straub M, Knoll T, et al. Metabolic evaluation and recurrence prevention for urinary stone patients: EAU guidelines. Eur Urol 2015;67:750-63.

4. Fernstrom I, Johansson B. Percutaneous pyelolithotomy. A new extraction technique. Scand J Urol Nephrol 1976;10:257-9.
5. Turk C, Knoll T, Petrik A, et al. Guidelines on urolithiasis. http:// uroweborg/guideline/urolithiasis/ (accessed 5 Sep 2015).

6. Borofsky MS, Lingeman JE. The role of open and laparoscopic stone surgery in the modern era of endourology. Nat Rev Urol 2015;12:392-400.

7. Rizvi SA, Sultan $\mathrm{S}$, ljaz $\mathrm{H}$, et al. Open surgical management of pediatric urolithiasis: a developing country perspective. Indian J Urol 2010;26:573-6.

8. Netto Junior N, Lemos GC, Fiuza JL. Percutaneous nephrolithotomy in patients with previous renal surgery. Eur Urol 1988;14:353-5.

9. Basiri A, Karrami H, Moghaddam SMH, et al. Percutaneous nephrolithotomy in patients with or without a history of open nephrolithotomy. J Endourol 2003;17:213-16.

10. Margel D, Lifshitz DA, Kugel V, et al. Percutaneous nephrolithotomy in patients who previously underwent open nephrolithotomy. $J$ Endourol 2005;19:1161-4.

11. Lojanapiwat B. Previous open nephrolithotomy: does it affect percutaneous nephrolithotomy techniques and outcome. J Endourol 2006;20:17-20.

12. Sofikerim M, Demirci D, Gülmez I, et al. Does previous open nephrolithotomy affect the outcome of percutaneous nephrolithotomy? J Endourol 2007;21:401-3.

13. Kurtulus FO, Fazlioglu A, Tandogdu Z, et al. Percutaneous nephrolithotomy: primary patients versus patients with history of open renal surgery. J Endourol 2008;22:2671-5.

14. Tugcu V, Su FE, Kalfazade N, et al. Percutaneous nephrolithotomy (PCNL) in patients with previous open stone surgery. Int Urol Nephrol 2008;40:881-4.

15. Falahatkar S, Panahandeh Z, Ashoori E, et al. What is the difference between percutaneous nephrolithotomy in patients with and without previous open renal surgery? J Endourol 2009;23:1107-10.

16. Gupta NP, Mishra S, Nayyar R, et al. Comparative analysis of percutaneous nephrolithotomy in patients with and without a history of open stone surgery: single center experience. J Endourol 2009;23:913-16.

17. Resorlu B, Kara C, Senocak C, et al. Effect of previous open renal surgery and failed extracorporeal shockwave lithotripsy on the performance and outcomes of percutaneous nephrolithotomy. $J$ Endourol 2010;24:13-16.

18. Gupta R, Gupta A, Singh G, et al. PCNL-a comparative study in nonoperated and in previously operated (open nephrolithotomy/ pyelolithotomy) patients-a single-surgeon experience. Int Braz $J$ Urol 2011;37:739-44.

19. Zhang $\mathrm{H}$, Pei $\mathrm{Q}$, Cui $\mathrm{H}$, et al. Effect of history of open nephrolithotomy on percutaneous nephrolithotomy. Chin J Geriatr 2011;30:578-80.

20. Yesil S, Ozturk U, Goktug HN, et al. Previous open renal surgery increased vascular complications in percutaneous nephrolithotomy (PCNL) compared with primary and secondary PCNL and extracorporeal shock wave lithotripsy patients: a retrospective study. Urol Int 2013;91:331-4.

21. Onal B, Gevher F, Argun B, et al. Does previous open nephrolithotomy affect the outcomes and complications of percutaneous nephrolithotomy in children? J Pediatr Urol 2014;10:730-6.

22. Aldaqadossi HA, Kotb Y, Mohi K. Efficacy and safety of percutaneous nephrolithotomy in children with previous renal stone operations. J Endourol 2015;29:878-82.

23. Ozgor F, Kucuktopcu O, Sarılar O, et al. Does previous open renal surgery or percutaneous nephrolithotomy affect the outcomes and complications of percutaneous nephrolithotomy. Urolithiasis 2015;43:541-7

24. Telli $\mathrm{O}$, Haciyev $\mathrm{P}$, Karimov $\mathrm{S}$, et al. Does previous stone treatment in children generate a disadvantage or just the opposite? Urolithiasis 2015;43:141-5.

25. Moher D, Liberati A, Tetzlaff J, et al. Preferred reporting items for systematic reviews and meta-analyses: the PRISMA statement. BMJ 2009;339:b2535.

26. Wells G, Shea B, O'Connell D, et al. The Newcastle-Ottawa Scale (NOS) for assessing the quality of nonrandomised studies in meta-analyses. http://www.ohri.ca/programs/clinical_epidemiology/ oxford.asp (accessed 5 Sep 2015).

27. Hozo SP, Djulbegovic B, Hozo I. Estimating the mean and variance from the median, range, and the size of a sample. BMC Med Res Methodol 2005:5:13.

28. Khorrami M, Hadi M, Sichani MM, et al. Percutaneous nephrolithotomy success rate and complications in patients with previous open stone surgery. Urol J 2014;11:1557-62.

29. Tefekli A, Esen T, Olbert PJ, et al. Isolated upper pole access in percutaneous nephrolithotomy: a large-scale analysis from the CROES percutaneous nephrolithotomy global study. J Urol 2013;189:568-73. 